\title{
Removal of Erioglaucine Dye from Aqueous Medium Using Ecofriendly Synthesized $\mathrm{ZnMnO}_{3}$ Photocatalyst
}

\author{
A.V. Borhade, ${ }^{*}$ D. R. Tope, and G. B. Dabhade \\ Department of Chemistry, Research Centre, HPT Arts and RYK Science College, Nasik, MS, India
}

(Received 27 May 2017; Accepted 13 June 2017; Published 29 July 2017)

\begin{abstract}
The hexagonal nanocrystalline $\mathrm{ZnMnO}_{3}$ powder was prepared from activated mixture by an ecofriendly solid state reaction using mechanochemical method. The synthesized catalyst was characterized by various investigative analytical techniques like Fourier Transform Infrared Spectroscopy (FT-IR), Ultraviolet-diffused reflectance Spectroscopy (UV-DRS), X-ray Diffraction (XRD), Scanning Electron Microscopy (SEM) with EDAX, Transmission Electron Microscopy (TEM) and Brunauer-Emmett-Teller (BET) surface area. The average particle size of $\mathrm{ZnMnO}_{3}$ was found to be $82 \mathrm{~nm}$. The photocatalytic activity of the prepared $\mathrm{ZnMnO}_{3}$ nanoparticles have been investigated by the degradation of Erioglaucine dye. It is revealed that the product exhibits a pronounced photocatalytic activity under the influence of UV-visible light irradiation. The degradation mechanism of Erioglaucine in presence of $\mathrm{ZnMnO}_{3}$ was established by using LC-MS technique.

[DOI: $10.1380 /$ ejssnt.2017.74]
\end{abstract}

Keywords: Ecofriendly; Photocatalysts; Erioglaucine; Dye degradation; UV-visible

\section{INTRODUCTION}

Most of the catalysts used in modern chemical industry are based on metal oxides [1], among which perovskite type of oxides remain dominant [2]. The perovskite type of metal oxides have attracted attention as challenging catalysts for auto exhaust control since $1970[3-6]$. Perovskite has general formula $\mathrm{ABO}_{3}$ with "A" cation has 12 fold coordination with oxygen anions and 6 fold by "B" cation. In recent years, the applications of perovskite have been investigated on the elimination of carbon monoxide from exhaust emission [7] Numerous techniques have been employed to prepare perovskite material $[8,9]$. The preparation method is of crucial importance for the properties of the obtained perovskite [10]. However, many synthesis methods require assistance of extra surfactants [11, 12], crystal seeds, capping agent [13], special precursor or template [14].

It is worth noting that $\mathrm{ZnMnO}_{3}$ is used as protective coating for electrodes which improve the efficiency of seawater electrolysis for hydrogen production $[15,16]$. Furthermore, cubic $\mathrm{ZnMnO}_{3}$ could find applications in electronics, as it exhibits excellent reproducible unipolar resistive switching behavior [17]. Apart from these interesting possibilities cubic $\mathrm{ZnMnO}_{3}$ in a broad range of application and the current knowledge of its physical properties is very limited. Apart from these applications, literature survey reveals that no work is available on photocatalytic activity of hexagonal $\mathrm{ZnMnO}_{3}$ perovskite.

Undoubtedly, the use of extra surfactants, templates or other additives during synthesis of perovskite brings about higher cost, more complex purification procedure, and higher level of pollution to the environment. The synthetic organic dyes and refractory chemicals are toxic, which can generate intense color and are highly hazardous to the environment especially to the aquatic life. Photocatalytic degradation of organic compound and dyes

\footnotetext{
* Corresponding author: ashokborhade2007@yahoo.co.in
}

by semiconductor under UV irradiation after a visible approach to the solution of a variety of environmental problems [18, 19], because of their incomplete use and washing operations considerable amount of dyes have been noticed in textile waste water [20]. The photocatalytic degradation of organic dyes were carried out using various inorganic and some organic materials such as $\mathrm{Ba}_{2} \mathrm{TeO}\left(\mathrm{PO}_{4}\right)_{2}$ [21], $\mathrm{TiO}_{2}$ [22], OCPUFPDA [23], $\mathrm{Ce}$ Doped $\mathrm{GeO}_{2}$ [24]. The organic dyes are found in suspension or dissolved state in the waste water [25]. UVvisible light-induced photocatalyst have received considerable attention because visible light occupies main part of solar light. The development of future generation of photocatalyst material is important for the efficient use of light. Nevertheless, there are insufficient reports in literature on photocatalytic activity of perovskite. Present study reveals that it is an urgent need to find an effective heterogeneous metal oxide photocatalyst for cleaning an environment and to check the catalytic efficiency. The use of available methods for removal of organic matter from an effluents is energy guzzling and lead to exhaustic evolution of $\mathrm{CO}_{2}$ and develops global warming and contributes in greenhouse effect. Hence, there is a vast scope of undertaking investigations of synthesis of the catalyst under ecofriendly condition and which will work in harmony with environment. It is worthwhile solution to extend the research in the diversified field of the perovskite catalyst $\left(\mathrm{ZnMnO}_{3}\right)$. Thus, considering the diversity and unique physiological and light driven photocatalytic activities, a study of synthesis and characterization of efficient ecofriendly solid state photocatalyst by mechanochemical method and its application for degradation of Erioglaucine dye in presence of UV-visible light has been undertaken.

In the present work, water soluble Erioglaucine (mol. wt. $792, \mathrm{C}_{37} \mathrm{H}_{3} 4 \mathrm{Na}_{2} \mathrm{~N}_{2} \mathrm{O}_{9} \mathrm{~S}_{3}$ ) was selected, which is an acid blue dye. Acid dyes are the best for dyeing the new fibers silk; Acid blue Erioglaucine is carcinogenic. It also produces an increased incidence of kidney tumors in mice after its oral administration. Thus, keeping the hazardous nature and harmful effects in view, it is worthwhile to 
remove Erioglaucine systematically from aqueous solution using $\mathrm{ZnMnO}_{3}$ as a green photocatalyst.

\section{EXPERIMENTAL}

\section{A. Materials and methods}

The chemicals used for the synthesis of $\mathrm{ZnMnO}_{3}$ photocatalyst are $\mathrm{ZnO}$ and $\mathrm{MnO}_{2} \quad(99.99 \%$ pure, Sigma Aldrich), and are used without further purification. The muffle furnace (TEMPO; Instrument and Equipment PVT; Serial No. 219, 240 Volts, $1.6 \mathrm{~kW}$ Cat. No.$36 \mathrm{P})$ was used to calcine reaction mixture. The dye Erioglaucine (see Fig. 1) was purchased from Sigma Aldrich (lot\#mkBG3545v, Pcode 1001005329, CAS: 3544-45-9) and deionized water were used as solvent. The photochemical reactor (Srinivasan-Griffin-Rayonet Type, Prism Electronic Systems) was equipped with quartz tube placed at the center in presence of UV source for irradiation.

\section{B. Synthesis of $\mathrm{ZnMnO}_{3}$ photocatalyst}

Here we report on synthesis of hexagonal $\mathrm{ZnMnO}_{3}$ based on ecofriendly mechanochemical solid state method at high temperature. The equimolar mixture of $\mathrm{ZnO}$ and $\mathrm{MnO}_{2}$ was grinded by mortar and pestle to acquire fine powder for $25 \mathrm{~min}$, and calcinated at $500^{\circ} \mathrm{C}$ for $3 \mathrm{~h}[26]$. Again the calcinated powder was further heated at $850^{\circ} \mathrm{C}$. The calcination was continued for next twenty hours with grinding and milling. The resulting powder of $\mathrm{ZnMnO}_{3}$ obtained was characterized by Fourier transform infrared spectroscopy (FTIR-Shimadzu IR affinity1), UV-visible diffused reflectance spectroscopy (UV-DRSShimadzu 2450), X-ray diffraction (XRD-SVNIT), Scanning Electron Microscopy (SEM-SVNIT) with EDAX, Transmission Electron Microscopy (TEM-make Philips, Model CM 200, Operating voltages 20-200 kV, Resolution, 2.4 AO SAIF, IIT, Bombay) and Brunner-EmmetTeller (BET-CSMRI).

\section{Photocatalytic performance}

The photocatalytic activity of synthesized catalyst was checked by photodegradation of Erioglaucine dye on exposure to light. The experiment was performed in three cases. In the first case, to evaluate effect of photocatalyst in presence of UV-visible light with $0.2 \mathrm{gm}, \mathrm{ZnMnO}_{3}$ photocatalyts was suspended in $100 \mathrm{~mL}$ of $10 \mathrm{mg} / \mathrm{L}$ dye solution and exposed to the light. In second case, to evaluate the effect of UV-visible light in absence of photocatalyst, only dye solution was irradiated with light. In third case, in absence of light by using $100 \mathrm{~mL}$, aqueous solution, with $10 \mathrm{mg} / \mathrm{L}$ concentration, dye solution containing same amount of photocatalyst was kept in dark. The effect of UV-visible light or photocatalyst on dye solution was studied by analyzing aliquots on UV-visible spectrometer (950-Perkin-Elmer) after every $10 \mathrm{~min}$.

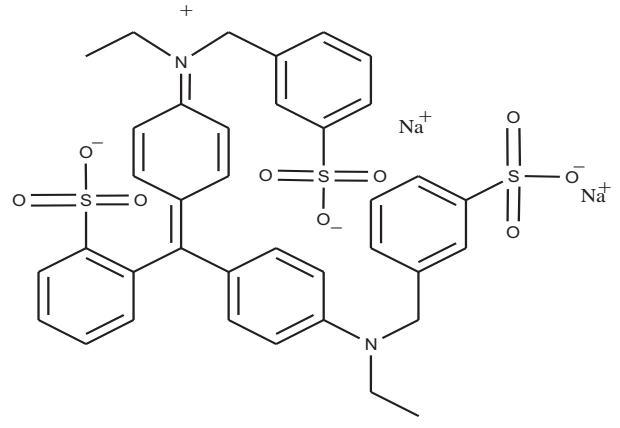

FIG. 1. Structure of Erioglaucine dye.

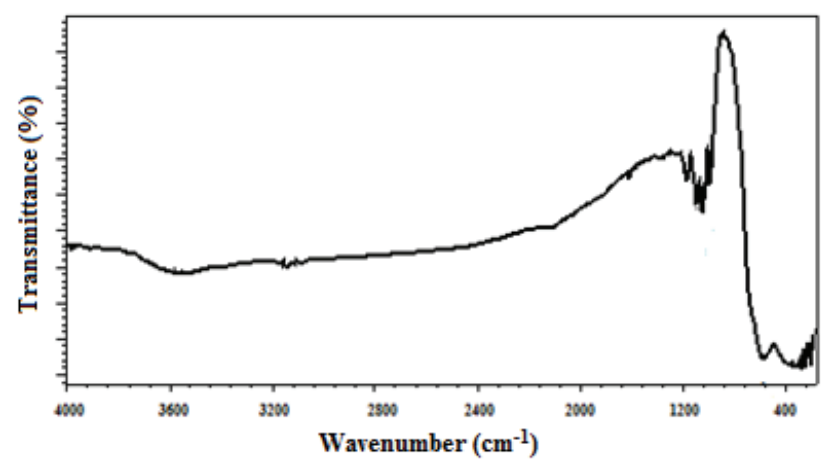

FIG. 2. FT-IR spectrum of synthesized $\mathrm{ZnMnO}_{3}$ photocatalyst.

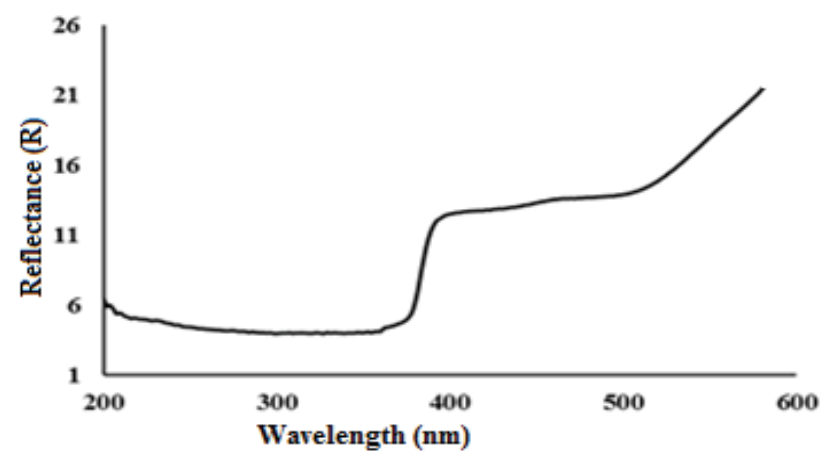

FIG. 3. UV-DRS spectrum of synthesized $\mathrm{ZnMnO}_{3}$ photocatalyst.

\section{RESULTS AND DISCUSSION}

\section{A. Characterizations of $\mathrm{ZnMnO}_{3}$ photocatalyst}

The typical infrared spectrum (Fig. 2) confirms, the formation of $\mathrm{ZnMnO}_{3}$ photocatalyst. The vibrational frequency band at $611.46 \mathrm{~cm}^{-1}$ confirms the presence of $\mathrm{Zn}-$ $\mathrm{O}$, The peaks between $902 \mathrm{~cm}^{-1}$ to $1099 \mathrm{~cm}^{-1}$ assigned to the stretching vibration of $\mathrm{Mn}-\mathrm{O}-\mathrm{Mn}$.

The optical absorption of prepared $\mathrm{ZnMnO}_{3}$ catalyst powder was recorded using UV-visible spectrometer and is depicted in Fig. 3. The sample $\mathrm{ZnMnO}_{3}$ shows absorption 


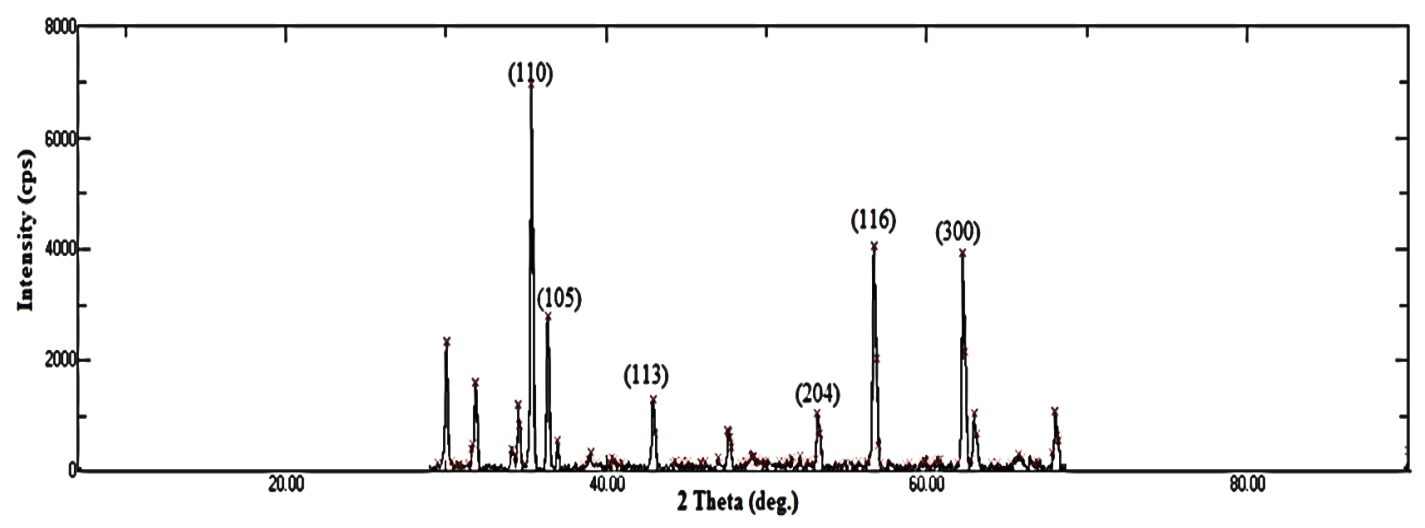

FIG. 4. XRD spectrum of synthesized $\mathrm{ZnMnO}_{3}$ photocatalyst.

from the UV with edge cut off at $391 \mathrm{~nm}$. This can be ascribed to the band gap of $3.17 \mathrm{eV}$, which is less than the band gap of $\mathrm{ZnO}, 3.65 \mathrm{eV}$. The broad absorption peaks may be due to the uneven surface area, shape and size hence the $\mathrm{ZnMnO}_{3}$ shows good phtocatlytic activity as compared to $\mathrm{ZnO}$. The band gap energy is calculated by the equation, $E g=\frac{h c}{\lambda}=\frac{1243}{\lambda(\mathrm{nm})}$ (Where, $E g=$ band gap energy, $h=$ Plank's constant, $c=$ velocity of light, $\lambda=$ wavelength in nm.).

Figure 4 shows that the X-ray diffraction pattern of the $\mathrm{ZnMnO}_{3}$ perovskite powder synthesized in this study. The spectrum at theta matches well with the peaks in the JCPDS data card no. 28-1468. Only the characteristic diffraction peaks of perovskite-type structure with a hexagonal symmetry are observed in $\mathrm{ZnMnO}_{3}$ catalyst calcined under air at $850^{\circ} \mathrm{C}$ for $20 \mathrm{~h}$. The peaks at an angle of $35.34,38.73,41.28,49.93,54.30,63.15$ and 64.98 indicate (110), (105), (113), (204), (116), (214) and (300) respectively confirming hexagonal phase. Furthermore, the average particle size for $\mathrm{ZnMnO}_{3}$ from the range of $65 \mathrm{~nm}$ to $85 \mathrm{~nm}$ were calculated by using standard DebyeScherrer equation $D=\frac{K \lambda}{\beta \cos \theta}[27-29]$, where $D$ is the particle size; $\mathrm{K}$ is a crystalline shape constant $(\mathrm{K}=0.94) ; \lambda$ is X-ray wavelength $(\lambda=1.5406 \AA) ; \theta$ is Bragg diffraction angle and $\beta$ is flex width which is converted into radian.

The surface morphology and its chemical composition of the synthesized photocatalyst are analyzed by SEM image (Fig. 5) and it clearly shows better agglomeration because of nanocrystalline nature of $\mathrm{ZnMnO}_{3}$. Although an agglomerates are irregular size, the fine particles are mostly below $100 \mathrm{~nm}$ in size. The EDAX confirms the presence of $\mathrm{Zn}, \mathrm{Mn}$ and $\mathrm{O}$ elements in synthesized photocatalyst.

The structure of $\mathrm{ZnMnO}_{3}$ was further investigated by TEM and its selective area of the diffraction pattern (SAED) (Fig. 6). As can be seen from Fig. 6, the pure sample consists of irregular particles with aggregated structure. The average particle size obtained by TEM method was found to be $82 \mathrm{~nm}$. It is clear from the SAED pattern, crystal structure of the catalyst is hexagonal. The dark spot in the SAED pattern reveals hexagonal perovskite phase of $\mathrm{ZnMnO}_{3}$ which is in good agreement with XRD pattern of catalyst.

The BET surface area measurement of nanocrystaline

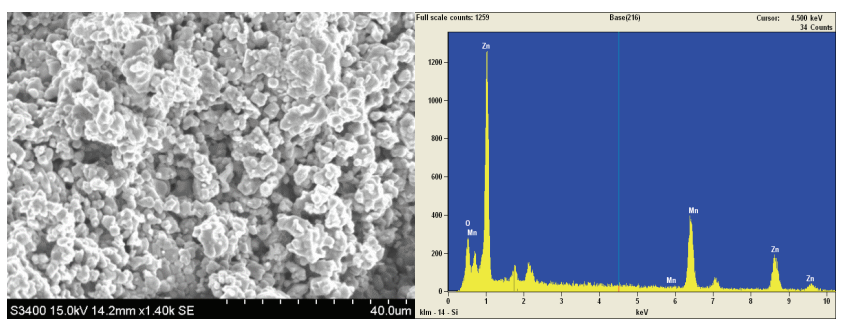

FIG. 5. SEM and EDAX analysis of synthesized $\mathrm{ZnMnO}_{3}$ photocatalyst.
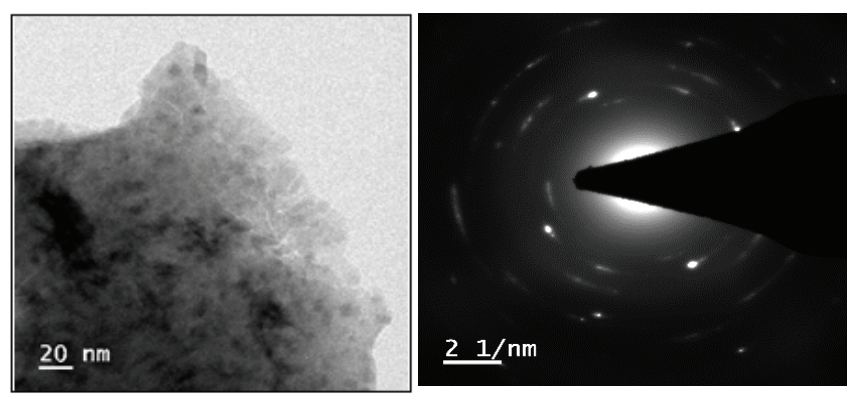

FIG. 6. TEM and SAED analysis of synthesized $\mathrm{ZnMnO}_{3}$ photocatalyst.

$\mathrm{ZnMnO}_{3}$ is shown in Fig. 7. The $\mathrm{N}_{2}$ adsorption / desorption isotherm is of typical IV-type with $\mathrm{H} 1$ hysteresis. The BET surface area obtained by this method is $8.941 \mathrm{~m}^{2} / \mathrm{g}$. The BJH pore size distribution shows that, the pore diameter $\left(D_{\mathrm{p}}\right)$ is $175.87 \AA$ and pore volume $\left(V_{\mathrm{p}}\right)$ is $0.002636 \mathrm{~cm}^{3} / \mathrm{gm}$.

\section{B. Photocatalytic degradation of erioglaucine dye using $\mathrm{ZnMnO}_{3}$}

\section{Effect of amount of catalyst}

The $10 \mathrm{mg}, 20 \mathrm{mg}, 30 \mathrm{mg}, 40 \mathrm{mg}$ and $50 \mathrm{mg}$ doses of catalysts were used to perform the experiment under the influence of UV irradiation at slightly acidic $\mathrm{pH}$ value of dye 


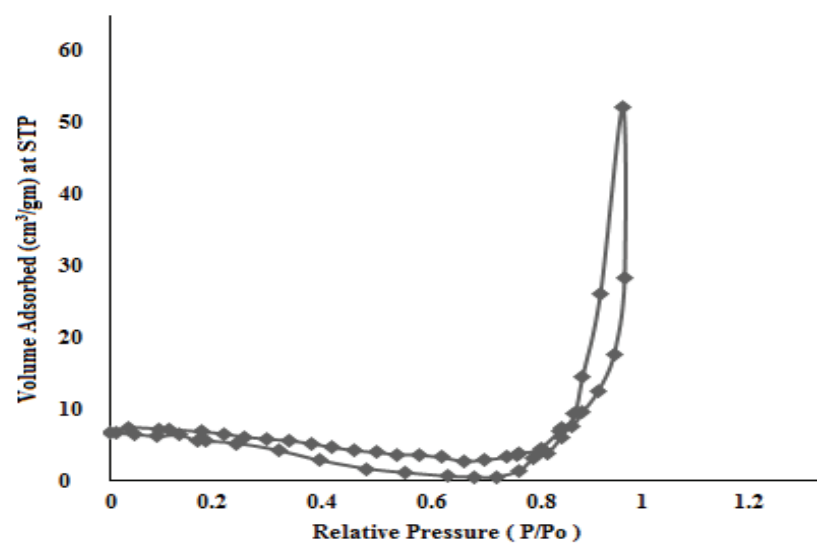

FIG. 7. BET Surface area of synthesized $\mathrm{ZnMnO}_{3}$ photocatalyst.

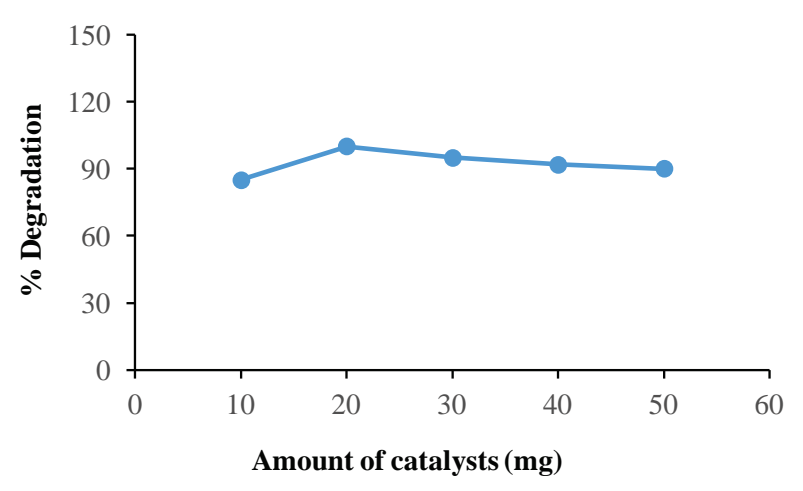

FIG. 8. Effect of amount of photocatalyst on degradation of Erioglaucine dye.

solution. No degradation of dye was found in the absence of catalysts, but Fig. 8 clearly indicates that $20 \mathrm{mg}$ catalysts loading gave better results than the other dosages fed to the reactor at the same $\mathrm{pH}$ value. It is further observed that the complete Erioglaucine dye degradation was found in $2 \mathrm{hr}$ in presence of $\mathrm{ZnMnO}_{3}$. The decolonization reaction kinetics were studied for $\mathrm{ZnMnO}_{3}$ photocatalysts. Dye degradation level was estimated using the subsequent equation [30].

$$
\text { Degradation rate }(\%)=\frac{1-C_{i}}{C_{0}} \times 100
$$

Where, $C_{0}$ is an initial concentration of the prepared Erioglaucine dye solution and $C_{i}$ the concentration of dye at time $t$.

\section{Effect of dye concentration}

The photocatalytic efficiency was studied by conducting the experiment using solutions of Erioglaucine dye with initial concentrations of $2 \mathrm{ppm}, 4 \mathrm{ppm}, 6 \mathrm{ppm}, 8 \mathrm{ppm}$ and $10 \mathrm{ppm}$. The increase in dye concentration shows decrease in efficiency (Fig. 9). The 10 ppm concentration gave better results. The degradation of dye with different concentration is in better agreement with previous

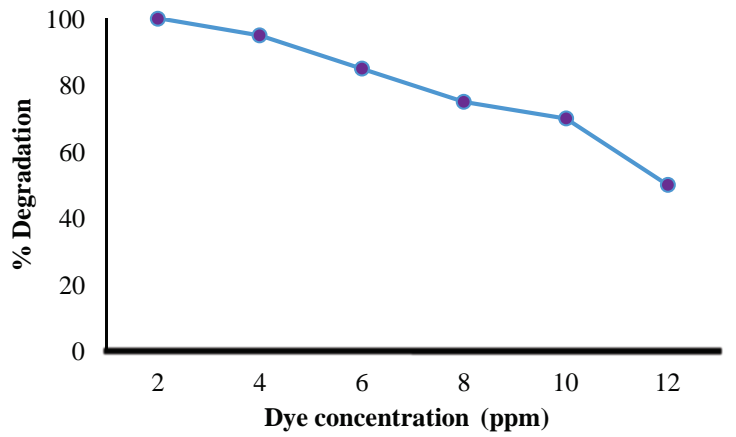

FIG. 9. Effect of dye concentration on dye degradation.

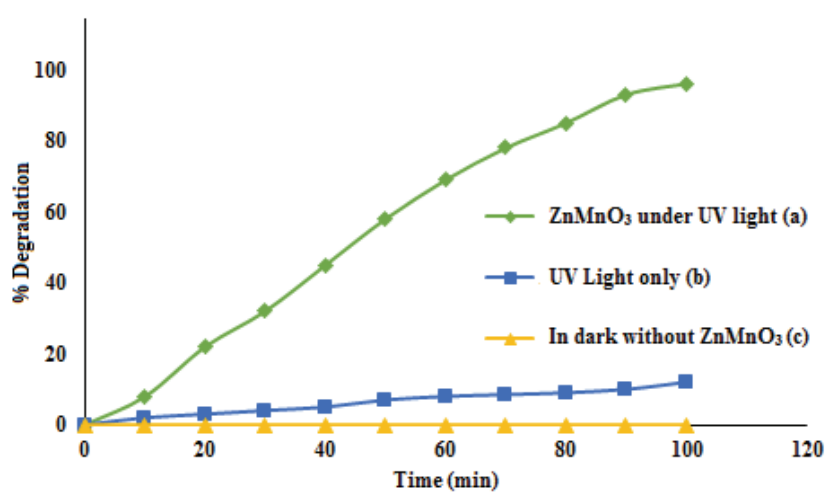

FIG. 10. Percentage degradation of Erioglaucine in presence of $\mathrm{ZnMnO}_{3}$.

reports [31, 32].

Results of the degradation of Erioglaucine dye in presence and absence of $\mathrm{ZnMnO}_{3}$ catalyst under UV-visible light irradiation are illustrated in Fig. 10. In the absence of $\mathrm{ZnMnO}_{3}$, Erioglaucine degraded neither under UV-visible light irradiation nor in the dark, it was the degradation experiment carried out by taking $10 \mathrm{ppm}$, $100 \mathrm{ml}$ Erioglaucine dye solution with $20 \mathrm{mg}$ photocatalyst. The decrease in color intensity of dye solution was checked by measuring optical density of solution at an interval of every $10 \mathrm{~min}$.

A curve-a in Fig. 10 indicates that the degradation of Erioglaucine dye when $20 \mathrm{mg} \mathrm{ZnMnO}_{3}$ photocatalyst per $100 \mathrm{~mL}$ dye was exposed to UV-visible light. In the same figure, curve-b depicts that the photodegradation of Erioglaucine takes place weakly in absence of the photocatalyst with UV-visible light irradiation . Only when dye solution was kept in dark, no decrease in absorbance was observed, which is depicted by curve-c.

Monitoring the photocatalytic degradation process by UV-visible spectrometry (Fig. 11) was needed to verify the fast photochemical breakdown of chromophoric groups present in the Erioglaucine molecule. These chromosphere groups are the cause behind the characteristics dark colorization of the Erioglaucine solution; the color of sample (absorbance at $624 \mathrm{~nm}$ ) decreased remarkably reaching a decolourisation. As seen in Fig. 11, the absorbance of Erioglaucine decreased to almost zero within 70 min using $\mathrm{ZnMnO}_{3}$ nanoparticles.

The results also confirms that for species adsorbed 


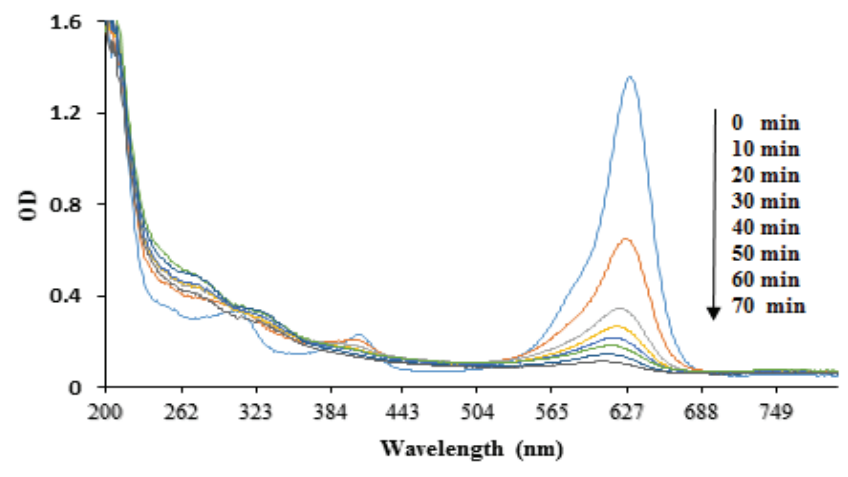

FIG. 11. UV-visible spectral changes of degraded Erioglaucine dye with time dye.

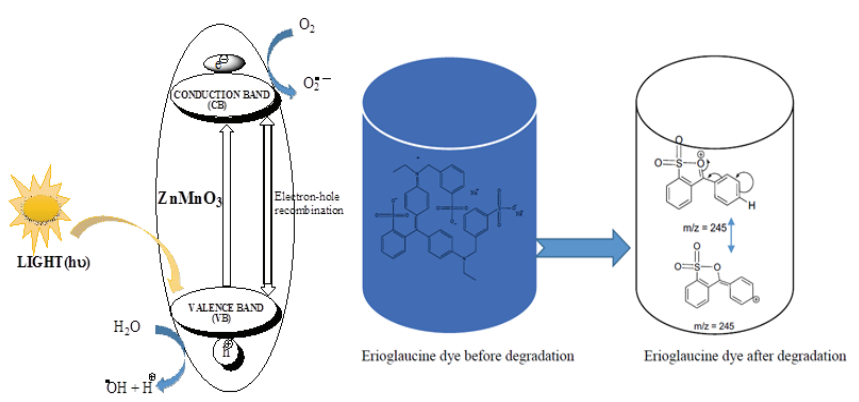

FIG. 12. Proposed mechanism of degradation of Erioglaucine dye in presence of $\mathrm{ZnMnO}_{3}$ photocatalyst.

on $\mathrm{ZnMnO}_{3}$ the hole-transfer reaction can successfully compete with the electron-hole recombination processes. The following interfacial photochemical reactions were described.

$$
\begin{aligned}
& \mathrm{ZnMnO}_{3}+h \nu(\mathrm{UV}) \\
& \rightarrow \mathrm{ZnMnO}_{3}\left(\mathrm{e}_{\text {conduction band }}^{-}+\mathrm{h}_{\text {valence band }}^{+}\right)
\end{aligned}
$$

In the $\mathrm{ZnMnO}_{3}, \mathrm{~h}^{+}$in the valence band easily reacts with surface bound $\mathrm{H}_{2} \mathrm{O}$ to produce $\mathrm{H}^{+}$and $\mathrm{OH}^{\bullet}$ radicals, whereas superoxide radical anion of oxygen $\left(\mathrm{O}_{2}^{\bullet-}\right)$ is produced by the combination $\mathrm{O}_{2}$ and $\mathrm{e}^{-}$in the conduction band of $\mathrm{ZnMnO}_{3}$.

$$
\begin{gathered}
\mathrm{ZnMnO}_{3}\left(\mathrm{~h}_{\text {valence band }}^{+}\right)+\mathrm{H}_{2} \mathrm{O} \\
\rightarrow \mathrm{ZnMnO}_{3}+\mathrm{H}^{+}+\mathrm{OH}^{\bullet} \\
\mathrm{ZnMnO}_{3}\left(\mathrm{e}_{\text {conduction band }}^{-}+\mathrm{O}_{2}\right. \\
\rightarrow \mathrm{ZnMnO}_{3}+\mathrm{O}_{2}^{\bullet-}
\end{gathered}
$$

A superoxide radical anion of oxygen $\left(\mathrm{O}_{2}^{\bullet-}\right)$ produced in above reaction and it is again combined with water to produce unstable $\mathrm{OH}^{\bullet}$ radicals.

$$
\begin{aligned}
& \mathrm{O}_{2}^{\bullet-}+\mathrm{H}_{2} \mathrm{O} \rightarrow \mathrm{H}_{2} \mathrm{O}_{2} \\
& \mathrm{H}_{2} \mathrm{O}_{2} \rightarrow 2 \mathrm{OH}^{\bullet}
\end{aligned}
$$

Above reaction prevents the recombination of electron and hole, which was obtained in the first step, then the $\mathrm{OH}^{\bullet}$ radical reacts with dye and it gives degraded prod-

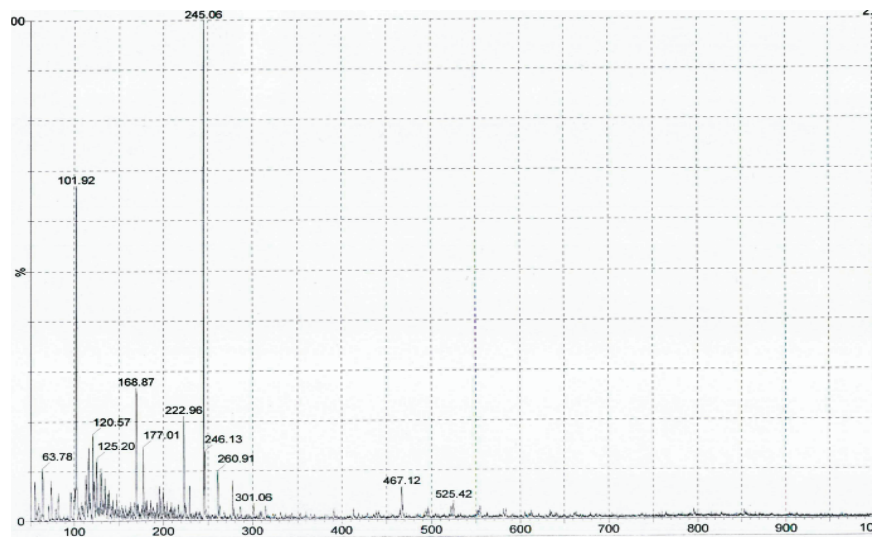

FIG. 13. Liquid chromatography-mass spectrometry LC-MS of degraded dye.

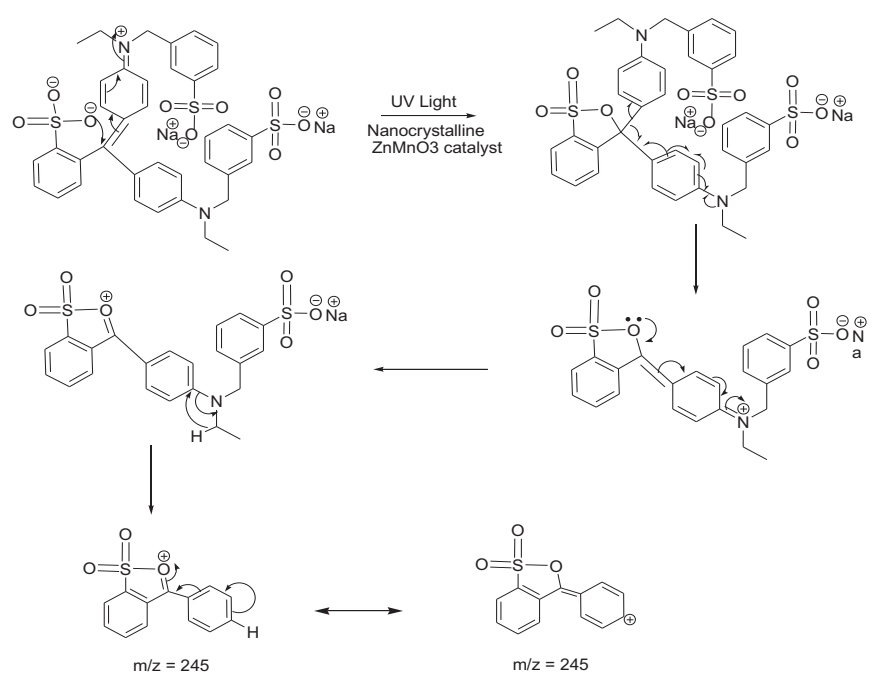

FIG. 14. Degradation Mechanism of Erioglaucine dye.

ucts, so net results are shown in following reactions.

$$
\begin{aligned}
& \text { Erioglaucine dye }+\mathrm{OH}^{\bullet} \\
& \rightarrow \text { degradation products } \\
& \begin{aligned}
\text { Erioglaucine dye } & +\mathrm{h}_{\text {valence band }}^{+} \\
\rightarrow & \text { oxidation products } \\
\text { Erioglaucine dye } & +\mathrm{e}_{\text {conduction band }}^{-} \\
\rightarrow & \text { reduction products }
\end{aligned}
\end{aligned}
$$

All above reactions of photocatalysis are only possible in presence of dissolved oxygen in water. Considering above degradation mechanism, here we proposing a possible mechanism for hydroxyl radical and superoxide radical. Figure 12 depicts the proposed mechanism for radical formation.

\section{Liquid chromatography-mass spectrometry (LCMS) of degraded erioglaucine dye}

After complete degradation of Erioglaucine dye, the solution was undertaken to determine the structure of 


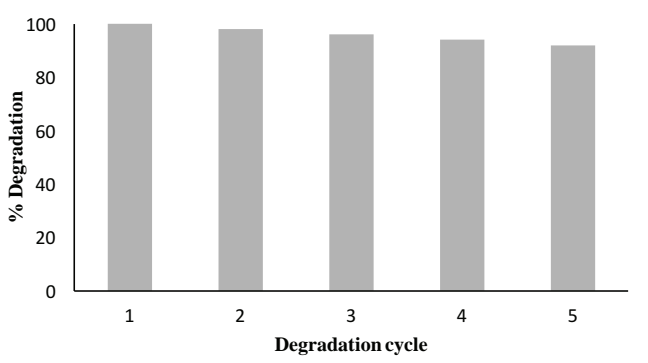

FIG. 15. Reusability of $\mathrm{ZnMnO}_{3}$ photocatalyst against Erioglaucine dye.

products by using HPLC-MS. Figure 13 shows liquid chromatography-mass spectrum of degraded Erioglaucine dye with different peaks of fragments. Using these fragments, the major Erioglaucine dye pathway is proposed and is depicted in Fig. 14.

The parent molecule peak of Erioglaucine dye is observed at $792 \mathrm{~m} / \mathrm{z}$ before applying any irradiation, only parent dye presents as expected. Several fragment at 102 $\mathrm{m} / \mathrm{z}, 121 \mathrm{~m} / \mathrm{z}, 135 \mathrm{~m} / \mathrm{z}, 223 \mathrm{~m} / \mathrm{z}, 277 \mathrm{~m} / \mathrm{z}$ and $466 \mathrm{~m} / \mathrm{z}$ that occurs after the degradation of dye. The possible fragmentation of Erioglaucine dye after degradation is shown in Fig. 14.

\section{Reusability of photocatalyst against erioglaucine dye}

The recyclability of synthesized catalysts $\mathrm{ZnMnO}_{3}$ was also studied (Fig. 15). After every use, the photocatalyst was washed three times with ethanol and dried at $50^{\circ} \mathrm{C}$ and redistributed in fresh dye solution. The $\mathrm{ZnMnO}_{3}$ catalyst showed favorable reusability after recycling five times. We observed some extent of loss of catalytic activity of each cycle. The decrease in degradation rate may due to weakening of the absorbance ability of the catalysts or the loss of some catalysts during the collection.

\section{CONCLUSIONS}

The $\mathrm{ZnMnO}_{3}$ photocatalyst was synthesized by green chemistry approach with cost effective mechanochemical method along with periodic calcination. The average particle size, band gap energies, surface area and surface morphology with its photocatalytic activity was studied in details by photocatalytic degradation of Erioglaucine dye. The efficient photodegradation of dye by using $\mathrm{ZnMnO}_{3}$ photocatalyst in presence UV light is very attractive response in the field of photodegradation, and this work may provide the new direction to researcher into the development of photocatalyst in short time with cost effective and ecofriendly applications.

\section{ACKNOWLEDGMENTS}

Authors are thankful to the Council of Scientific and Industrial Research, New Delhi for financial support to carry out this work.
[1] X.-Y. Yu, Z.-G. Liu, and X.-J. Huang, Trends Environ. Anal. Chem. 3, 28 (2014)

[2] M. A. Pena, and J. L. G. Fierro, Chem. Rev. 101, 1981 (2001).

[3] A. S. Bhalla, R. Guo, and R. Roy, Mater. Res. Innov. 4, 3 (2000).

[4] Y. Wen, C. Zhang, H. He, Y. Yu, and Y. Teraoka, Catal. Today 126, 400 (2007).

[5] T.-J. Huang, C.-Y. Wu, and C.-C. Wu, Electrochem. Commun. 13, 755 (2011).

[6] D. Fino, N. Russo, G. Saracco, and V. Specchia, Prog. Solid State Chem. 35, 501 (2007).

[7] F. Patel and S. Patel, Procedia Eng. 51, 324 (2013).

[8] B. Levasseur and S. Kaliaguine, Appl. Catal. A 343, 29 (2008).

[9] A. Weidenkaff, Adv. Eng. Mater. 6, 709 (2004).

[10] C. Michel, M. Hervieu, J. Provost, and B. Raveau, Synth. Met. 33, 109 (1989).

[11] X. Su, F. Xiao, Y. Li, J. Jian, Q. Sun, and J. Wang, Mater. Lett. 64, 1232 (2010).

[12] C. Pan, D. Zhang, and L. Shi, J. Solid State Chem. 181, 1298 (2008).

[13] Z. Jiao, J. Wang, L. Ke, X. W. Sun, and H. V. Demir, ACS Appl. Mater. Interfaces 3, 229 (2011).

[14] H. X. Bai, X. H. Liu, and Y. C. Zhang, Mater. Lett. 63, 100 (2009).

[15] K. Izumiya, E. Akiyama, H. Habazaki, A. Kawashima, K. Asami, K. Hashimoto, and N. Kumagai, J. Appl. Elec- trochem. 27, 1362 (1997).

[16] L. V. Saraf, P. Nachimuthu, M. H. Engelhard, and D. R. Baer, J. Sol-Gel Sci. Technol. 53, $141(2010)$.

[17] H. Peng and T. Wu, Appl. Phys. Lett. 95, 152106 (2009).

[18] R. Asahi, T. Morikawa, T. Ohwaki, K. Aoki, and Y. Taga, Sci. 293, 269 (2001).

[19] A. L. Linsebigler, G. Lu, and J. T. Yates, Chem. Rev. 95, 735 (1995).

[20] S. Chakrabarti and B. K. Dutta, J. Hazard. Mater. 112, 269 (2004).

[21] C. H. S. Reddy, K. Sreenu, J. R. Reddy, G. Ravi, R. Guje, M. Malathi, and M. Vithal, Indian J. Chem. 55A, 9 (2016).

[22] R. Shetty, G. Kothari, A. S. Tambe, B. D. Kulkarni, and S. P. Kamble, Indian J. Chem. 55A, 16 (2016).

[23] L. Lefebvre, J. Kelber, L. Jierry, V. Ritleng, and D. Edouard, J. Environ. Chem. Eng. 5, 79 (2017).

[24] T. Wei, L. Z. Pei, and N. Lin, e-J. Surf. Sci. Nanotech. 14, 4 (2016).

[25] Y. Xu, J. Jia, D. Zhong, and Y. Wang, Chem. Eng. J. 150, 302 (2009).

[26] A. V. Borhade and Y. R. Baste, Arab. J. Chem. 10, 404 (2012).

[27] L. Alexander and H. P. Klug, J. Appl. Phys. 21, 137 (1950).

[28] A. L. Patterson, Phys. Rev. 56, 978 (1939).

[29] A. Monshi, M. R. Foroughi and M. R. Monshi, World J. Nano Sci. Eng. 2, 154 (2012). 
[30] R. Scipioni, D. Gazzoli, F. Teocoli, O. Palumbo, A. Paolone, N. Ibris, S. Brutti, and M. A. Navarra, Membranes 4, 123 (2014).

[31] A. P. Toor, A. Verma, C. K. Jotshi, P. K. Bajpai, and V. Singh, Dyes Pigments 68, 53 (2006).
[32] C.-C. Liu, Y.-H. Hsieh, P.-F. Lai, C.-H. Li, and C.-L. Kao, Dyes Pigments 68, 191 (2006). 